\title{
Voltammetric Behavior of the Transfer of Mono- and Polyammonium Ions across a Phospholipid Monolayer at the Nitrobenzene/Water Interface
}

\author{
Hajime Katano, *广 Yuji Murayama,* Hirosuke Tatsumi,* Takao Hibi,* Tokuji Ikeda,* \\ Ikuo KAMEOKA, ${ }^{* *}$ and Toshihide TsuKaTANI** \\ *Department of Bioscience, Fukui Prefectural University, Matsuoka, Fukui 910-1195, Japan \\ **Research and Development Division, Nicca Chemical, Co. Ltd., Bunkyo, Fukui 910-8670, Japan
}

\begin{abstract}
The influence of a phospholipid, dipalmitoyl phosphatidylcholine, layer at a nitrobenzenelwater interface on the transfer of tetraethylammonium ion and a polyammonium anti-fungus agent, poly[(dimethylimino)(2-oxo-1,2-ethanediyl)imino1,6-hexanediylimino(1-oxo-1,2-ethanediyl)(dimethylimino)-1,6-hexanediyl] ion, across the interface was studied by normal pulse voltammetry. When the phospholipid was adsorbed to form a monolayer at the nitrobenzenelwater interface by its addition to the organic phase, the half-wave potential in the current $v s$. potential curves for the transfer of tetraethylammonium ion did not change, but the limiting current was significantly decreased at certain sampling times, indicating a retarding effect of the layer on the ion-transfer. On the other hand, in the current $v s$. potential curves for the transfer of the polyammonium ion, no significant change in either the half-wave potential or the limiting current was observed upon adding the phospholipid, indicating that the polyammonium ion can easily permeate through the phospholipid layer. The results suggest a new application of the voltammetric technique to the study of cell membrane permeability to polyionic bioactive compounds.
\end{abstract}

(Received August 9, 2005; Accepted September 21, 2005)

\section{Introduction}

Recently, the voltammetric behavior of the transfer of polyions, ${ }^{1-5}$ including biologically active polyions, protamine ${ }^{3,5}$ and heparin, ${ }^{4}$ across the organic solventlwater (W) interface has been examined. In a previous paper, ${ }^{6}$ we reported on the voltammetric behavior of the transfer of polyammonium ions, including poly[(dimethylimino)(2-oxo-1,2-ethanediyl)imino1,6-hexanediylimino(1-oxo-1,2-ethanediyl)(dimethylimino)1,6-hexanediyl] (PA) ion, which has been used as anti-fungus agent, at the nitrobenzene (NB)|W interface. Despite their polydispersity, we observed both, by normal pulse voltammetry, S-shaped current vs. potential curves with the well-defined limiting currents and, by cyclic voltammetry, a pair of anodic and cathodic peak currents due to their ion-transfer across the $\mathrm{NB} / \mathrm{W}$ interface within the potential window.

The voltammetric study has been extended to the ion-transfer across a phospholipid, dipalmitoyl phosphatidylcholine (DPPC), layer at the NBIW interface. For a comparison, the transfer of tetraethylammonium $\left(\mathrm{TEA}^{+}\right)$ion, on which a retarding effect of phospholipid layer was reported, ${ }^{7-9}$ has also been studied. In this note, we describe mainly the results of normal pulse voltammetry of the transfer of $\mathrm{TEA}^{+}$and PA ions across the phospholipid layer, which was formed by the adsorption of DPPC from the bulk NB-phase. From the change in the limiting current of the normal pulse voltammograms (NPVs), it was shown that PA ion is more permeable through the phospholipid layer than $\mathrm{TEA}^{+}$ion.

\section{Experimental}

L- $\alpha$-Dipalmitoyl phosphatidylcholine DPPC was obtained from NOF Corp. and used as received. The polyammonium ion was obtained as an electrolyte (PACl), poly[(dimethylimino)(2-oxo1,2-ethanediyl)iminio-1,6-hexanediylimino(1-oxo-1,2-ethanediyl) (dimethylimno)-1,6-hexanediyl dichloride]. The weight-average molecular weight of the polyammonium salt $\left(M_{\mathrm{w}}\right)$ was 24000 and the polydispersity $\left(M_{\mathrm{w}} / M_{\mathrm{n}}, M_{\mathrm{n}}\right.$ being the number-average molecular weight) was $1.43 .{ }^{6}$ Reagent-grade tetraethylammonium chloride was obtained from Wako Pure Chemical Industries, Ltd. and used as received. The preparation of tetrapentylammonium tetraphenylborate (TPnATPB) and the purification of tetrapentylammonium chloride (TPnACl) and $\mathrm{NB}$ are described in Ref. 6. Other chemicals were of reagent grade and used as received.

The electrochemical cell used for recording NPV of the transfer of $\mathrm{TEA}^{+}$ion across the NBIW interface can be represented by cell-I:

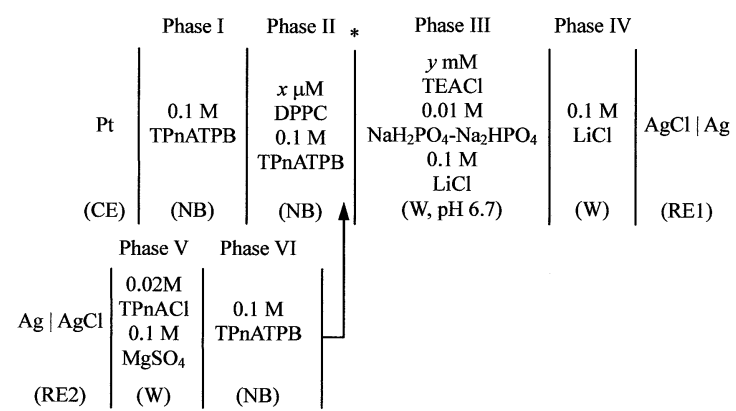

† To whom correspondence should be addressed. 


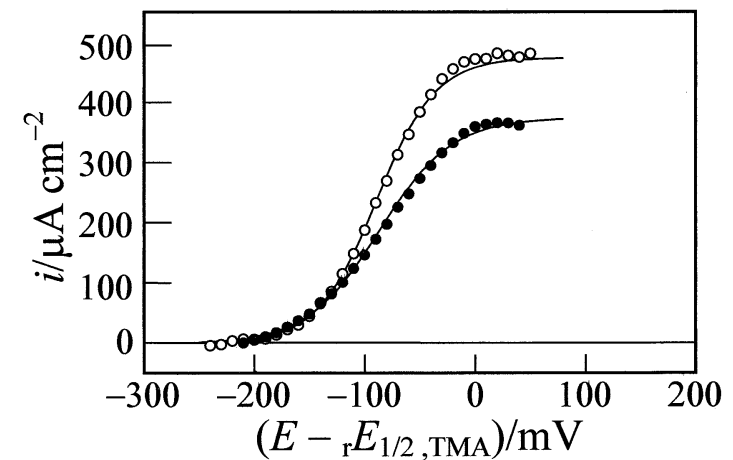

Fig. 1 Normal pulse voltammograms at the $0.1 \mathrm{M}$ TPnATPB (NB) $\mid 0.20 \mathrm{mM}$ TEACl, $0.01 \mathrm{M} \mathrm{NaH}{ }_{2} \mathrm{PO}_{4}-\mathrm{Na}_{2} \mathrm{HPO}_{4}, 0.1 \mathrm{M} \mathrm{LiCl}$ (W, $\mathrm{pH}$ 6.7) interface in the absence $(\mathrm{O})$ and presence $(\bullet)$ of $200 \mu \mathrm{M}$ DPPC in the NB-phase. Sampling time, $t_{\mathrm{s}}=0.006 \mathrm{~s}$.

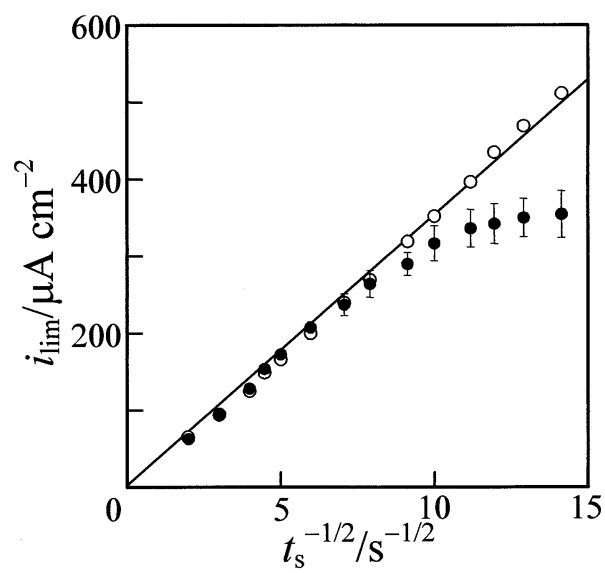

Fig. 2 Plots of $i_{\text {lim }} v s . t_{\mathrm{s}}^{-1 / 2}$ for the transfer of $0.20 \mathrm{mM} \mathrm{TEA}^{+}$ion across the NB/W interface in the absence $(\mathrm{O})$ and presence $(\bullet)$ of 200 $\mu \mathrm{M}$ DPPC in NB-phase.

where $\mathrm{M}=\mathrm{mol} \mathrm{dm}^{-3}$. The polarized NBIW interface, that is, the test interface, is indicated by an asterisk. The electrolytic cell used in this study was essentially the same as that described elsewhere. ${ }^{6}$ The surface area of the test interface was 0.038 $\mathrm{cm}^{2}$.

The applied potential $(E)$ is defined as the terminal potential of RE1 referred to that of RE2. The solution resistance between the two reference electrodes was about $3 \mathrm{k} \Omega$ for cell-I. The $E$ was controlled by a potentiostat furnished with a positivefeedback $i R$ compensation circuit. In this paper, the $E$-values in voltammograms are reported against the reversible half-wave potential of the transfer of tetramethylammonium $\left(\mathrm{TMA}^{+}\right)$ion across the $\mathrm{NB} / \mathrm{W}$ interface $\left({ }_{\mathrm{r}} E_{1 / 2, \mathrm{TMA}}\right)$ which was determined to be ${ }_{1} E_{1 / 2, \mathrm{TMA}}=379 \pm 3 \mathrm{mV}$ by normal pulse voltammetry with cell-I, in which Phase III was replaced by $0.20 \mathrm{mM}$ TMACl, $0.01 \mathrm{M} \mathrm{NaH}_{2} \mathrm{PO}_{4}-\mathrm{Na}_{2} \mathrm{HPO}_{4}, 0.1 \mathrm{M} \mathrm{LiCl}$ (W, pH 6.7).

In normal pulse voltammetry, a potential pulse, $\Delta E=E-E_{\mathrm{i}}$, $E_{\mathrm{i}}$ being the initial potential where the current due to the iontransfer is negligibly small, was applied to the NBIW interface at $t=0$, and the resulting current was sampled at $t=t_{\mathrm{s}}, t_{\mathrm{s}}$ being the sampling time. The potential step was ended, and the applied potential was held at $E_{\mathrm{i}}$ for a waiting period of $t_{\mathrm{w}}(=5 \mathrm{~s}$, in this study) The sampling of the pulse voltammetric current (I) at $t_{\mathrm{s}}$ was repeated with a voltage increment of $10 \mathrm{mV}$ on $\Delta E$ to obtain the $I-E$ curves, that is, NPVs. In Figs. 1, 2, and 3 below,

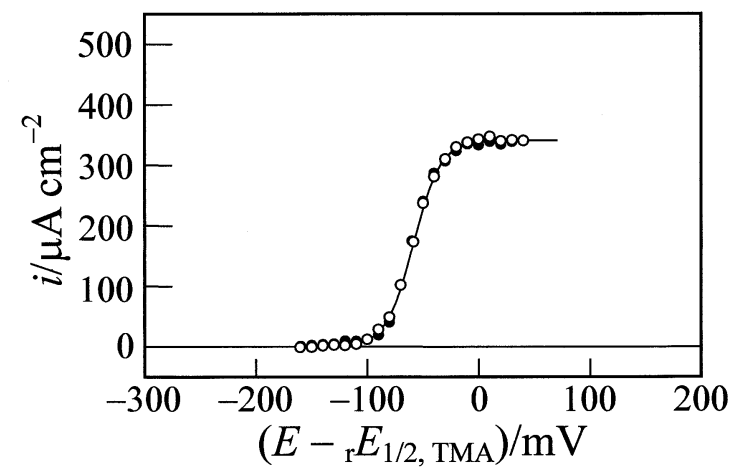

Fig. 3 Normal pulse voltammograms at the $0.1 \mathrm{M}$ TPnATPB (NB) $1100 \mathrm{mg} \mathrm{dm}{ }^{-3} \mathrm{PACl}, 0.01 \mathrm{M} \mathrm{NaH} \mathrm{PO}_{4}-\mathrm{Na}_{2} \mathrm{HPO}_{4}, 0.1 \mathrm{M} \mathrm{LiCl}$ $(\mathrm{W}, \mathrm{pH}$ 6.7) interface in the absence $(\mathrm{O})$ and presence $(\bullet)$ of $200 \mu \mathrm{M}$ DPPC in NB-phase. Sampling time, $t_{\mathrm{s}}=0.006 \mathrm{~s}$.

the current was recorded after the correction for the base current, and is reported as the current density $(i)$.

The test NBIW interface was freshly prepared before each voltammetric measurement. When DPPC was present in the NB-phase, the voltammetric measurement was started at least thirty minutes after preparation of the interface for the reproducibility of the voltammetric data.

All of the experiments were performed at $25 \pm 1^{\circ} \mathrm{C}$.

\section{Results and Discussion}

The NPV of the transfer of $0.20 \mathrm{mM} \mathrm{TEA}^{+}$ion across the $0.1 \mathrm{M}$ TPnATPB (NB)|0.01 M NaH $2 \mathrm{PO}_{4}-\mathrm{Na}_{2} \mathrm{HPO}_{4}, 0.1 \mathrm{M} \mathrm{LiCl}(\mathrm{W}$, $\mathrm{pH}$ 6.7) interface is shown by the open circles in Fig. 1. The $\mathrm{S}$ shaped $I-E$ curves with well-defined limiting currents were observed at the NBIW interface. The limiting current $\left(I_{\text {lim }}\right)$ was proportional to the concentration of the $\mathrm{TEA}^{+}$ions in the $\mathrm{W}$ phase, ${ }^{*} c_{\text {TEA }}^{\mathrm{W}}$, between 0.025 and $0.50 \mathrm{mM}$ at $t_{\mathrm{s}}=0.10 \mathrm{~s}$ and to $t_{\mathrm{s}}{ }^{-1 / 2}$ in the range of $t_{\mathrm{s}}$ between 0.005 and $0.25 \mathrm{~s}$ at $* c c_{\mathrm{TEA}}^{\mathrm{W}}=0.20$ $\mathrm{mM}$, as shown by the open circles in Fig. 2. The result indicates that the limiting currents are controlled by the diffusion of the ammonium ion in $\mathrm{W}$-phase. Using the theoretical equation of the limiting-diffusion current of NPV,${ }^{10}$ the diffusion coefficient of $\mathrm{TEA}^{+}$ion in the $\mathrm{W}$-phase was calculated to be $(1.03 \pm 0.02) \times$ $10^{-5} \mathrm{~cm}^{2} \mathrm{~s}^{-1}$, which coincides with the reported value. ${ }^{10}$ The slope of $E$ vs. $\log \left[I /\left(I_{\lim }-I\right)\right]$ plots and the intercept, that is, the half-wave potential, were almost independent of $t_{\mathrm{s}}$ in the range tested, and was determined to be $60 \pm 1 \mathrm{mV}$ and $-88 \pm 5 \mathrm{mV} v \mathrm{~s}$. ${ }_{\mathrm{r}} E_{1 / 2, \mathrm{TMA}}$, respectively. These results indicate that the $I-E$ curve obtained in the range of $t_{\mathrm{s}}$ tested can be assigned to a reversible NPV.

The S-shaped I-E curves with well-defined limiting currents were also observed at the NB/W interface in the presence of DPPC in the NB-phase. No significant change in both the slope and the intercept of the $E v s . \log \left[I /\left(I_{\lim }-I\right)\right]$ plots was observed by the addition of DPPC in the NB-phase up to $250 \mu \mathrm{M}$. However, $I_{\lim }$ at $t_{\mathrm{s}}=0.006 \mathrm{~s}$ decreased with increasing concentration of DPPC in the NB-phase $\left({ }^{*} c_{\mathrm{DPPC}}^{\mathrm{O}}\right)$ to approach a constant value when $* c_{\mathrm{DPPC}}^{\mathrm{O}}$ was more than several tens of micromolar, indicating that the monolayer was formed by adsorbing the DPPC from the bulk NB-phase and retarded the transfer of $\mathrm{TEA}^{+}$ion. As an example, the NPV for the transfer of $0.20 \mathrm{mM} \mathrm{TEA}^{+}$ion across the layer at the NB/W interface when $* c_{\mathrm{DPPC}}^{\mathrm{O}}=200 \mu \mathrm{M}$ at $t_{\mathrm{s}}=0.006 \mathrm{~s}$ is shown by the full circles in Fig. 1. 
The dependence of $I_{\text {lim }}$ when $* c_{\mathrm{DPPC}}^{\mathrm{O}}=200 \mu \mathrm{M}$ on $t_{\mathrm{s}}^{-1 / 2}$ is shown by the full circles in Fig. 2. $I_{\text {lim }}$ was in agreement with that when $* c_{\mathrm{DPPC}}^{\mathrm{O}}=0$ in the range of $t_{\mathrm{s}}>c a .0 .04 \mathrm{~s}$, and was smaller than that when ${ }^{*} c_{\mathrm{DPPC}}^{\mathrm{O}}=0$ in the range of $t_{\mathrm{s}}<c a .0 .04 \mathrm{~s}$. Similar dependence of $I_{\mathrm{lim}}$ on $t_{\mathrm{s}}$ to that in Fig. 2 was obtained for the transfer of other ammonium ions, such as tetramethylammonium, trimethylphenylammonium, and acetylcholine ions, across the DPPC layer at the NBIW interface. The dependence may be explained by a similar model of the diffusion current to ensembles of microelectrodes. ${ }^{11,12}$ The study is continuing.

The NPV for the transfer of PA ion across the $0.1 \mathrm{M}$ $\begin{array}{lllllll}\text { TPnATPB } & \text { (NB) } 100 \quad \mathrm{mg} \quad \mathrm{dm}^{-3} & \mathrm{PACl}, & 0.01 & \mathrm{M}\end{array}$ $\mathrm{NaH}_{2} \mathrm{PO}_{4}-\mathrm{Na}_{2} \mathrm{HPO}_{4}, 0.1 \mathrm{M} \mathrm{LiCl}\left(\mathrm{W}, \mathrm{pH}\right.$ 6.7) interface at $t_{\mathrm{s}}=$ $0.006 \mathrm{~s}$ is shown by the open circles in Fig. 3. $I_{\mathrm{lim}}$ was proportional to the concentration of the $\mathrm{PACl}$ in the $\mathrm{W}$-phase $\left({ }^{*} c_{\mathrm{PACl}}^{\mathrm{W}}\right)$ between 20 and $200 \mathrm{mg} \mathrm{dm}^{-3}$ at $t_{\mathrm{s}}=0.05 \mathrm{~s}$, and also to $t_{\mathrm{s}}^{-1 / 2}$ in the range of $t_{\mathrm{s}}$ between 0.005 and $0.25 \mathrm{~s}$ at $* c_{\text {PACl }}^{\mathrm{W}}=100$ $\mathrm{mg} \mathrm{dm}{ }^{-3}$, indicating that the limiting current is controlled by the diffusion of the PA ion in the W-phase. With decreasing $t_{\mathrm{s}}^{-1 / 2}$, the slope of the $E v s . \log \left[I /\left(I_{\lim }-I\right)\right]$ plots decreased and the intercept shifted to more negative potential slightly, and the extrapolated values of the slope and intercept were determined to be $9 \pm 1 \mathrm{mV}$ and $-64 \pm 2 \mathrm{mV} v s$. ${ }_{\mathrm{r}} E_{1 / 2, \mathrm{TMA}}$, respectively. ${ }^{6}$

The NPV for the transfer of PA ion across the DPPC layer at the NBIW interface when $* c_{\mathrm{DPPC}}^{\mathrm{O}}=200 \mu \mathrm{M}$ is shown by the full circles in Fig. 3. Surprisingly, in the range of $t_{\mathrm{s}}$ tested, no significant change in $I_{\text {lim }}$, as well as the slope and intercept of the $E v s . \log \left[I /\left(I_{\lim }-I\right)\right]$ plots, was observed by the addition of DPPC in the NB-phase up to $250 \mu \mathrm{M}$. The results indicate that PA ion is rapidly permeable through the phospholipid layer from the W-phase to the NB-phase. Also, no significant change in NPV was observed for the transfer of another polyammonium ion, poly[(dimethylimino)-1,6-hexanediyl] ion, at the NBIW interface by the addition of DPPC in the NB-phase up to 250 $\mu \mathrm{M}$.

In potential sweep voltammograms for the transfer of TEA $^{+}$ ion at the NB/W interface, when the scan rate $(v)$ was higher than $c a .0 .1 \mathrm{~V} \mathrm{~s}^{-1}$, the anodic peak current and the anodic peak potential were lowered, and shifted to more positive potential by the addition of $200 \mu \mathrm{M}$ DPPC in the NB-phase. On the other hand, in potential sweep voltammograms for the transfer of PA ion in the range of $v$ tested $\left(v<1 \mathrm{~V} \mathrm{~s}^{-1}\right)$, no significant change in either the peak current or the peak potential was observed by the addition of DPPC in NB-phase up to $250 \mu \mathrm{M}$. The results indicate again the difference of the permeability of the two ions through the phospholipid layer.

The high permeability of the polyammonium ion through the phospholipid layer may be related to the elemental process in the anti-fungus action, e.g., disruption or rupture of cell membrane, ${ }^{13,14}$ or in drug delivery system with polyionic compounds. The present voltammetric study has been extended to other polyammonium anti-fungus agents. The voltammetric results and a relationship with the anti-fungus activity will be discussed in a following paper.

\section{Acknowledgements}

The authors express their thanks to support by a Projects Carried out with Fukui Prefectural Citizens' Participations, for Promotion of Research in Fukui Prefectural University towards Regional Contributions.

\section{References}

1. M. D. Osborne and H. H. Girault, J. Electroanal. Chem., 1994, 370, 287.

2. S. Ulmeanu, H. J. Lee, and H. H. Girault, Electrochem. Commun., 2001, 3, 539.

3. S. Amemiya, X. Yang, and T. L. Wazen-egger, J. Am. Chem. Soc., 2003, 125, 11832.

4. Z. Samec, A. Trojánek, J. Langmaier, and E. Samcová, Electrochem. Commun., 2003, 5, 867.

5. Y. Yuan, L. Wang, and S. Amemiya, Anal. Chem., 2004, 76,5570 .

6. H. Katano, I. Kameoka, Y. Murayama, H. Tatsumi, T. Tsukatani, and M. Makino, Anal. Sci., 2004, 20, 1581.

7. V. J. Cunnane, D. J. Schiffrin, and M. Fleischmann, J. Electroanal. Chem., 1988, 243, 455.

8. T. Kakiuchi, M. Kotani, J. Noguchi, M. Nakanishi, and M. Senda, J. Colloid Interface Sci., 1992, 149, 279.

9. T. Kakiuchi, T. Kondo, M. Kotani, and M. Senda, Langmuir, 1992, 8, 169

10. T. Kakutani, T. Osakai, and M. Senda, Bull. Chem. Soc. Jpn., 1983, 56.791 .

11. T. Gueshi, K. Tokuda, and H. Matsuda, J. Electroanal. Chem., 1978, 89, 247.

12. B. R. Scharifker, J. Electroanal. Chem., 1988, 240, 61.

13. T. Ikeda and S. Tazuke, Makromol. Chem., 1984, 185, 869.

14. T. Maeda and H. Kourai, Biosci. Ind., 2003, 61, 103. 